\title{
Avoiding Political Pitfalls Associated with School Mathematics Reforms
}

\author{
Patty Anne Wagner \\ Department of Mathematics, University of North Georgia, Dahlonega, United States \\ Email: patty.wagner@ung.edu
}

\begin{abstract}
Over the course of United States history, there have been numerous attempts to reform school mathematics in order to increase student achievement. Although the methods of reform have varied, a common theme has emerged: the reform encounters a political backlash that forces a retreat into traditional instructional materials and methods. Education leaders, including mathematics education coaches and specialists, are tasked with fostering school mathematics reforms and are unavoidably at the forefront of this ongoing political struggle. Unfortunately, the research community has offered little insight into how education leaders can effectively engage the critics of reforms. This research study examined the beliefs and motivations of the critics of mathematics education reforms and offers suggestions for how education leaders can avoid potential political pitfalls while effectively engaging with these critics.
\end{abstract}

Keywords: Education leadership, math wars, mathematics education, mathematics education reforms.

\section{Introduction}

For decades, the Unites States public has agreed that student achievement in mathematics needs to be improved, but sharp disagreement exists as to how that should be accomplished. A relative consensus does exist, however, among mathematics education researchers, teacher educators, and mathematics coaches, specialists, and other mathematics education leaders. One of the responsibilities of education leaders, including mathematics coaches and specialists, is to improve student achievement by fostering this vision of mathematics education. However, many have found their efforts thwarted by critics using the political process to undermine reforms. Little is known about the primary concerns of these critics, despite the fact that these controversies have existed in the U.S. since the 1990s and continue to play out regarding the Common Core State Standards in Mathematics (CCSSM) (National Governors Association Center for Best Practices [NGA] \& Council of Chief State School Officers [CCSSO], 2010).

Irrespective of the particular set of mathematics standards adopted by their state or district, individual mathematics education leaders have focused on facilitating the instructional practices and structures that are supported by the vast majority of mathematics education research. This requires leaders to describe and advocate this vision of mathematics education to teachers, parents, and other stakeholders. Unfortunately, some leaders have found their arguments to be ineffective or even counterproductive. Others have found themselves subject to unflattering media attention (Bubba, 2014; Champion News Online, 2013; Jessica M.J., 2014; Kane, 2014; Morgenstern, 2013). In some cases, critics' political activity has forced leaders to abandon reform efforts (Talbert, 2002; Wagner, 2014).

Although advocates of reforms have speculated on critics' objections (Battista, 1999; Becker \& Jacob, 2000; Kohn, 1998; O'Brien, 1999; Reys, 2001; Schoen, Fey, Hirsch, \& Coxford, 1999; Schoenfeld, 2004), no concerted effort in the form of research has deciphered the critics' motivations and conceptions of reform. Yet, an understanding of critics' viewpoints can enable leaders to anticipate and prepare for critics' arguments and avoid political pitfalls that may compromise their efforts.

This study was conceived to explore the motivations and conceptions of individuals who publicly oppose mathematics education reforms. The following research questions guided the study:

1. What experiences or affiliations do those who oppose school mathematics reforms in the U.S. have in common? 
2. What beliefs do these individuals share about mathematics as a domain?

3. What beliefs do they share about the goals of school mathematics and how those goals should be achieved?

4. How do these critics characterize school mathematics reforms and to what elements do they object?

5. How do they interpret and react to the evidence supporting school mathematics reforms?

In the following, I present relevant background literature, detail the methods and procedures used, present the findings, and discuss the implications of those findings for the work of educational leaders.

\section{$2 \quad$ Background}

Current research in mathematics education supports instructional practices and structures that have been variously labeled as reform or Standards-based. These reforms have been described in, among others, publications by the National Council of Teachers of Mathematics (NCTM) (1989, 2000, 2014) and have generated various levels of controversy in the United States since the early 1990s. The CCSSM (NGA \& CSSO, 2010) has more recently increased the focus on student achievement in mathematics, driving state and local efforts to develop teachers' understanding of mathematics education reforms. Whether or not the CCSSM survives in any given location, reform instructional practices and structures will continue to be emphasized as a way to increase student achievement. The NCTM describes this vision of school mathematics as, among other things, expectations and practices that facilitate a conceptual understanding of mathematics, that position students as mathematical thinkers and problem solvers, and that facilitate a more productive disposition towards mathematics. Perhaps most importantly, by attending to matters related to diversity, gender, and differentiation, the NCTM vision is one in which all students have opportunity for success in mathematics (NCTM, 2000; 2014).

Any attempt to facilitate education reforms can be analogized to policy implementation. Yannow (2000) described individuals reacting to policies as inhabiting communities of meaning: groups in which "cognitive, linguistic, and cultural practices reinforce each other, to the point at which shared sense is more common than not, and policy-relevant groups become 'interpretive communities' sharing thought, speech, practice, and their meanings" (p. 10). She described communities of meaning as groups that share common ways of framing a policy that depend on deeper commonalities of experiences, beliefs, or values. As an example of how one's experience can influence his or her interpretation, consider how a man who had once been bitten might react when a dog barks at him. To him, the dog is threatening whereas another bystander might simply interpret the dog's bark as a greeting. Yannow characterized communities of meaning as groups that interpret the various dimensions of a policy similarly and therefore, "speak the same language" in the way they react to, talk about, and characterize the policy and its effects.

Pierson (1993) noted that policies may create alliances between individuals and groups that heretofore had no motivation to see each other as allies. In particular, a common purpose underlies the alliances, but the motivation for political engagement of the individuals varies. In the same way, critics of mathematics education reforms likely share understandings that unite them in oppositional activities, but have significant differences in the ways they conceptualize the reforms. An understanding of the critics of mathematics education reforms, therefore, might depend on characterizing their respective communities of meaning.

Philipp's (2007) observation that beliefs shape individuals' interpretations of experiences highlights the need to attend to individual beliefs as a potential unifying element in communities of meaning. Pajares (1992) suggested a reflexive connection between beliefs and evidence, where beliefs may be based on evidence that has been internally modified to fit the belief.

\section{Methods}

I used a grounded theory qualitative approach as outlined by Corbin and Strauss (2008) because the goal was to develop a theoretical description of the beliefs and interpretations that describe the communities of meaning of the critics of school mathematics reforms. With grounded theory, data sources are not predetermined. Rather, the researcher follows an inductive process of data collection and 
analysis. "Analysis begins after the first day of data gathering. Data collection leads to analysis. Analysis leads to concepts. Concepts generate questions. Questions lead to more data collection so that the researcher might learn more about those concepts" (Corbin \& Strauss, pp. 144-145).

In order to focus on issues that transcended disputes unrelated to mathematics education reforms, I analysed individuals or groups who entered a public forum to make known their dissatisfaction at the nonlocal level. That is, I analysed critics whose political activities targeted mathematics education reforms generally, as opposed to specific district or school actions. In determining what specific data to begin with, I noted that critics of reforms often connected with each other virtually; therefore, I began with critics' written documents that were readily available on the Internet.

Most of the written documents of the initial data set were collected from the websites Mathematically Correct and New York City HOLD National. I chose these two sites because they presented themselves as representative of those who object to mathematics education reform policies in the U.S. and they offered a large number of articles by multiple authors who expressed their objections to the general ideas of school mathematics reforms. I initially collected articles indiscriminately, attempting to find articles reflecting a variety of authors. I then followed an iterative pattern of data collection and analysis, following leads from the data to help identify additional critics. For example, the author of one document contrasted his ideology with that of political conservatives that he claimed were also critics of the reforms. Noting that none of the data collected had evidenced an explicitly conservative viewpoint, I searched for documents specifically within politically conservative websites and publications to seek these critics. I also collected new data to answer questions arising from analysis. For example, I sought data describing the political perspectives of conservative critics in order to answer questions about why they evidenced particular concerns.

To identify communities of meaning, I looked for areas of commonality between multiple authors as opposed to capturing the views of a particular individual. I used QSR International's NVivo 10 (NVivo) qualitative data analysis software to aid my analysis of the documents, which involved developing hundreds of codes under broad categories. I eventually eliminated each code that did not "earn its way into the theory by repeatedly being present" (Corbin \& Strauss, 1990, p. 7). Although I was analysing through coding, I refrained from making final determinations of communities of meaning until I reached theoretical saturation, that is, the sense that all the categories had been completely captured based on the absence of any new concepts in subsequently collected data (Corbin \& Strauss, 2008). At this point, the data consisted of web pages, written documents posted to websites, commentaries, video, PowerPoint documents, books, and journal articles. They included 99 documents written by 41 authors, producing 1,800 coded references.

I initially avoided collecting data that referenced the CCSSM because I was interested in critics of instructional reforms as opposed to a particular policy. Only later, when codes were established, did I venture into some documents that addressed reforms at the nonlocal level within the context of the CCSSM. Tracing some critics' objections into the CCSSM controversy revealed that a subsection of the CCSSM critics object to the instructional vision of mathematics education reforms.

Finally, I employed a trial and error approach among possible themes of commonality to determine communities of meaning. Through this process, the core of each of the communities became clear. It is possible that some group or groups of critics existed that I did not discover. Therefore, I do not claim to present here an exhaustive overview of all critics of mathematics education reforms.

\section{Findings}

The critics in this study occupied one of three communities of meaning, distinguished by the primary lens through which each author viewed Grades K-12 mathematics and the reforms. It is possible for individuals to view experiences through multiple lenses; however, for the sake of clarity I placed each critic into a distinct community of meaning according to what appeared to be his or her primary lens. This resulted in unequal distributions of data within the communities of meaning and the number of coded references that each collection of data produced ranged widely (see Table 1).

The community of meaning that I called Education Traditionalists (ETs) encompassed 11 authors of various occupations. Some worked in STEM fields, whereas others' careers were far removed from mathematics. None of the ETs were academic mathematicians. 
Table 1. Distribution of Documents and Coded References among Communities of Meaning

\begin{tabular}{cccc}
\hline Community of Meaning & $\begin{array}{c}\text { Number of } \\
\text { Authors }\end{array}$ & $\begin{array}{c}\text { Number of } \\
\text { Documents }\end{array}$ & $\begin{array}{c}\text { Number of Coded } \\
\text { References }\end{array}$ \\
\hline Education Traditionalists & 11 & 21 & 165 \\
Math Traditionalists & 12 & 53 & 1,457 \\
Conservatives & 18 & 25 & 174 \\
\hline
\end{tabular}

The community of meaning that I called Math Traditionalists (MTs) represented the views of 12 authors, 11 of whom identified with the role of an academic mathematician, having currently or formerly served in such a role. The number of documents that fell into the MT community of meaning was about twice that in the ETs' and produced ten times of the number of coded references of the ET documents.

The community of meaning that I called Conservatives (CVs) emerged from documents written by 18 authors. The number of documents and coded references in the data set was similar to that of the ETs. The smaller number of coded references in the ETs' and the CVs' documents as compared to the MTs' was partly the product of fewer documents to code, but was more significantly due to ETs' and CVs' less nuanced and complex conceptions of Grades K-12 mathematics and the reforms.

\subsection{The Education-Traditionalists}

The ETs' views corresponded to those of academic-traditionalists. Significantly, ETs equated mathematics education reforms to progressive-experimentalist educational philosophies. The controversies over these two views of education reach back to the early 1900s in the United States when John Dewey famously challenged traditional views of education. A history can be pieced together by reading Hutchins (1936), Adler (1940), and Dewey (1937a, 1937b, 1941/1988). Briefly, the academictraditionalist philosophy holds that humanity's basic instincts are untrustworthy and that the qualities necessary for a civilized society are contrary to the human condition (Bagley, 1938; Hirsch, 2001; Hutchins; Kandel, 1938; Loveless, 2001). Consequently, academic-traditionalists view education as a means by which these qualities are cultivated via the disciplined and systematic acquisition of a reasonably fixed body of knowledge (Bagley; Hirsch; Kandel). Academic-traditionalists believe education should be characterized by the development of self-control and intellectual virtues (Hirsch; Hutchins), teacher-centered instruction (Loveless), and the dissection of subject-matter, both between and within subjects (Bagley; Hirsch). Academic-traditionalists hold subject matter in the highest regard, valuing it far more than social goals or learning processes, and they believe that students' knowledge of this subject matter can and should be systematically assessed. Although not all the ETs expressed familiarity with the traditionalist-progressivist controversy, the authors in this community of meaning evidenced the philosophical and educational understandings of academic-traditionalists.

Because the ETs assumed that children's natural inclinations cannot be trusted, they believed that education plays a critical role in children's development, where knowledgeable adults press learning on sometimes unwilling children. To the ETs, in mathematics this took the form of ensuring that children master fundamental skills to lay the foundation for future mathematical learning and problem solving. The ETs believed that teachers and students should begin with a focus on basic skills and procedures, particularly standard algorithms, and move "step by step" (Stotsky, 2009, para. 9) to higher levels of formality and applications. The ETs believed that proper dissection of the skills, along with effective direct instruction, is necessary for student learning. This view of learning mathematics correlated well with their conception of mathematics, which they described simply as hierarchical: "Mathematics is cumulative. The prerequisites accumulate as you move to the next topic of study" (Pappas, 2003).

The ETs suggested that practice is an important element of learning mathematics; however, they were careful not to promote drill. Carson, an ET, bristled under the suggestion that her "emphasis on math algorithms might result in the drill and kill approach" (Lehman College Multimedia Center, 2011, 03:51), emphatically stating, "First of all, there's no one advocating for a program that is nothing but drill. That's not even close. ... [But] the fact is children do need to practice" (03:52). The ETs similarly expressed defensiveness at what they perceived was an accusation that traditional instructional methods preclude conceptual understanding of mathematics. 
The ETs criticized mathematics education reforms for what they believed was an expectation that students engage in problem solving prior to having acquired the skills for properly doing so. Garelick (2005) protested, "While adherents believe that such an approach teaches 'mathematical thinking' rather than dull routine skills, some mathematicians have likened it to teaching someone to play water polo without first teaching him to swim" (para. 37). The ETs also expressed concern that mathematics education reforms de-emphasized basic skills and the learning of standard algorithms. Garelick (2013) wrote,

"I wouldn't be quite so much against the strategies that are taught in lieu of the standard algorithms, if they were used to help explain how the standard algorithms work, thus effecting the 'understanding' the reformers claim to be so concerned about. In actual practice, however, the alternatives are left by themselves. Students are left to work with partial sums and partial products (and other methods such as the lattice method for multiplication) in the early grades, and do not learn the standard algorithms until 4th and 5th grades" ("Balance," para. 7).

The ETs believed that the reforms privileged processes and social goals over content, and they therefore reacted to reform pedagogies with derision and skepticism. They flatly dismissed research supporting K-12 mathematics reforms on the basis that the research failed to meet scientific research standards or that it was produced by individuals or organizations that had something to gain by reporting positive outcomes. Instead, the ETs viewed mathematicians, particularly MTs (described below), as the authority for determining the content for school mathematics.

The ETs focused especially on what they believed would be the costs of reform instruction. They expressed particular concern for disadvantaged students. The ETs believed that although students from families with intellectual or financial capital had the resources to overcome the failures of schools to teach mathematics content appropriately, the "students who [would] pay the biggest price were those with the least to lose, those for whom the educational system has never worked very well" (Loveless, 2004, "Why Important," para. 1). The ETs predicted mathematics education reforms would increase social injustice and aggravate the achievement gap. Hirsch (1997) wrote:

"The oppressed class should be taught to master the tools of power and authority--the ability to read, write, and communicate -and should gain enough traditional knowledge to understand the worlds of nature and culture surrounding them. Children, particularly the children of the poor, should not be encouraged to follow "natural" inclinations, which would only keep them ignorant and make them slaves of emotion. They should learn the value of hard work, gain the knowledge that leads to understanding, and master the traditional culture in order to command its rhetoric" (p. 42).

Hirsch's words underscore the ETs' traditionalist lens, in which the natural instincts of the oppressed, as in all of humanity, are seen as untrustworthy, making it necessary for society to instill the qualities needed for individual success.

\subsection{The Math-Traditionalists}

The MTs spent more time characterizing mathematics than those in any other community of meaning. The MTs' primary lens was their view of mathematics, which underlay their primary concern about reform mathematics education: that it redefined what mathematics is and what constitutes success in it. When one MT was asked why he chose to invest so much time and effort in $\mathrm{K}-12$ mathematics education, he responded, "It enraged me to see a group of people going out of their way to, so to speak, corrupt mathematics" (Leong, 2013, p. 33).

It is important, then, to understand how the MTs view mathematics. Briefly, the MTs valued the coherent nature of mathematics as evidenced by their discussions of its internal structure and hierarchical nature. They claimed that what one knows in mathematics is dependent on previously proven facts and skills, most of which have been committed to memory. Wu (1999) wrote, "There are at least two special features about mathematics...: It is cumulative and it is precise" (p. 10). The MTs particularly valued precision as an element of mathematics, arguing that it is a critical component of mathematics that must be observed in mathematical discourse, as well as in formulating definitions and posing problems. Wu continued,

"The precision of mathematics stems from its abstract nature. Whereas even in a rigorous discipline such as physics, a photograph or a measurement by a laboratory equipment can render verbal 
explanations superfluous, the basic concepts of mathematics reside only in the realm of ideas and therefore must be meticulously described" (p. 10).

An important aspect of mathematics to the MTs was the role of proof, which was often referred to as deduction, logical reasoning, or mathematical reasoning. In the view of MTs, proof is closely related to conceptual understanding, for "students demonstrate genuine conceptual understanding when they can supply the mathematical reason for each step in a method" (Quirk, 2002, "How the NCEE Redefines Conceptual Understanding," para. 6).

The MTs' views of mathematics shaped their conceptions of K-12 mathematics education goals and how those goals could be achieved. Viewing mathematics as a coherent and sensible system, the MTs believed that children who are led through a well-designed program by a teacher with strong mathematical content knowledge will advance according to their capability. In the MTs' opinion, conceptual understanding is an eventual by-product of experience with the subject. In particular, the MTs described mathematics learning as an iterative process: introduction to new topics sheds light on previous learning as well as forms the basis for future learning. According to the MTs, a student's level of understanding when introduced to a new topic is unpredictable and dependent on previous learning. As a result, at times the best a student might do initially is memorized an algorithm or definition. The MTs asserted that, regardless of the level of understanding students bring to a new topic, their conceptual understandings will develop as they progress in their learning, enabling them to fill gaps in previous understandings. Quirk (2002) summarized MTs' view of mathematical learning in this way:

"Progress is slow at the beginning.... Progress is faster and faster as the knowledge base grows.... 'Understanding' grows as the knowledge base grows.... Example: A first grader needs to memorize $2+2$ $=4$, but a mathematically correct proof of this fact...must be delayed until the child has acquired a richer math knowledge base. Frequently we just need to memorize, to get the knowledge in our brain. Then the brain can do its magic, leading to what we call 'understanding'. Newly remembered knowledge is integrated with previously remembered knowledge and 'understanding' evolves. It may happen instantly, or it may take years" ("Traditional K-12 Math Education," para. 7).

This conception of learning mathematics reveals why the MTs may be untroubled by a student's short term use of "parroting." In the view of the MTs, this response may be a necessity until the student has developed the knowledge to establish a better understanding of the concept. The MTs argued that students must commit previously learned material to memory, for in doing so they free their working memory from trivial concerns. Thus MTs valued procedural fluency and accuracy, which they stated is achieved through practice. Absent memorization, MTs would argue, the iterative nature of learning fails.

The MTs believed that those involved in recommending mathematics education reforms lacked the content knowledge needed to make good judgments about teaching it. Situated within this context, the MTs interpreted the mathematical content of reform as inadequate, lacking attention to important fundamental skills, error-prone, and displaying unacceptable levels of informality. Wu (2011) stated, "The cumulative gap between what (research) mathematicians take for granted as mathematics and what teachers and educators perceive to be mathematics has caused enormous damage in mathematics education" (p. 382). Pattern problems were often cited as examples in which a lack of precision was problematic. Milgram (n.d.) complained:

"The fault is in the whole idea of expecting an answer to a problem of the form 'continue this pattern'. There are no incorrect answers to such a problem, for a pattern can be continued any way one likes with equal justice - unless the RULE for the pattern is made explicit and unambiguous" (p. 6).

The MTs insisted that the reformers' expectation for particular answers to pattern problems was mathematically erroneous.

The MTs objected to what they perceived to be the overuse of calculators and a de-emphasis of memorization and practice, as they believed these pedagogical practices would interfere with students' learning of fundamental skills. They also objected to what they perceived to be the inclusion of nonmathematical outcomes in assessments, which reflected their concern that reforms redefined what constitutes success in mathematics. They cited social goals, such as cooperation, communication, and mathematical disposition as examples of nonmathematical outcomes included in reform assessments.

Significantly, the MTs evidenced some alignment with the traditionalist view of education. Many of them expressed the view that the pedagogical practices of reform were a product of progressivist philosophy of teaching and learning, in which the interests of the child are considered paramount. To 
the MTs, reform pedagogical practices such as exploration and group work and the non-authoritative positioning of the teacher were attempts to entertain or coddle students rather than facilitate student learning. In describing the pedagogical practices of reform, the MTs painted a picture of students who have been given control of their learning in the interest of making mathematics fun. For example, Raimi (2004) observed, "The way to guarantee an education available to everyone is...to make it easy, and to make it fun" (para. 6).

\subsection{The Conservatives}

The CVs' primary lens was their conservative worldview. This does not imply that all, or even most, political conservatives in the U.S. reject mathematics education reforms. The CV's, however, shared a unique worldview that characterizes a segment of political conservatives in the U.S. To understand the concerns of CVs, it is necessary to understand this worldview, which I describe below and generally name conservative.

Conservatives believe that humankind is not naturally good. Therefore, they believe individuals require guidance and moral education to suppress their natural inclinations, and children need to be socialized by family, religion, and community to conform to social standards (Adams, 2009; Weinberger, 2011). In the view of conservatives, individuals are in a constant state of choice between good and evil, and maturity marks an individual who chooses self-control, responsibility, and duty to others (good) over his or her selfish desires (evil) (Conservapedia, 2013; Downing, 2001; Laser, 2010). Thus, they believe that individuals should be judged according to their personal choices and allowed to reap or suffer the consequences of those choices (Downing). Conservatives view competition as a method for motivating individuals to make choices that will improve their condition and, by extension, improve the community in which they live. Therefore, they assume and accept unequal outcomes, insisting instead on equal rights and opportunity (Laser).

Because conservatives believe in good and evil (i.e. right and wrong) and that these can be recognized, they believe that societies and cultures can be judged as conforming more or less to each. Therefore, they are unlikely to value unknown cultures or celebrate diversity. Rather, they embrace American culture and values, which are familiar to them and which they believe to be good (Downing, 2001).

In conservatives' view, liberals are driven by their sense of compassion (Laser, 2010) but fail to account for human nature; therefore, liberals' acts of compassion often have the unintended consequence of exacerbating problems by reducing or eliminating the consequences individuals would normally experience when they submit to their selfish tendencies. Conservatives suggest that liberals desire equal benefits for all, regardless of effort or product and that this philosophy is what is meant by the term social justice.

To conservatives, parents should have the ultimate say in their child's education and are in the best position to make those decisions. They believe, however, that educational experts consider themselves better judges of what is good for children than children's parents (e.g. Beck, 2013; Limbaugh, 2012). Conservatives believe that these experts are driven by their liberal ideology. They complain that educators promote practices focused on children's self-esteem to the extent that children are shielded from hard truths about the outcomes of their effort, which serves to distance children from the consequences of their actions and decisions (Limbaugh, 2007).

Through the lens of this worldview, the CVs expressed the opinion that the primary role of school mathematics should be to instill mastery of fundamental skills, of which standard algorithms are an important subset. They recommended direct instruction of content and extensive student practice to achieve this goal. The CVs viewed the teaching and learning of mathematics as a fairly straightforward endeavor, which could only be made complicated by "educrats... [who] believe in process - as opposed to educators, who believe in results" (Saunders, 2008, para. 3).

The CVs viewed mathematicians as experts in both the content and pedagogy of school mathematics. To the CVs, the existence of the MTs was evidence that the motivation behind the reforms was something other than students' mathematical learning. Specifically, they assumed that reforms were motivated by liberal ideology. They objected to what they saw as reform's reduced focus on correct answers, interpreting this as promoting moral relativism, which they viewed as part of a liberal agenda to cast doubt on any claim to absolute truth. The $\mathrm{CVs}$ also reacted negatively to claims that mathematics education reforms were a social justice issue, equating this term with liberal ideologies. 
Some CVs believed that a goal of mathematics education reforms was to "indoctrinate students with a pre-planned social agenda" (Chapman, 2013, para. 15). In particular, some CVs posited that the reforms were designed to create a wedge between parents and their children. Norton (2011) warned:

"It is a very real possibility that...all these other educators have embraced constructivist math not only for the social engineering aspects, but because it's another barrier between parent and child. Parents don't know how to do this method of math, so they may figure that it will serve to separate the parents a little further from their children and get children to believe that their teacher at school is the source of knowledge they should turn to" (para. 9).

The CVs complained that reform instruction de-emphasized basic skills. However, rather than providing a reason for why they found this problematic, the CVs derided the content changes, implying that they were the products of liberals acting on their unrealistic views of human nature, their desire for equal outcomes, or their belief that all cultures are worthy of celebration. In fact, the CVs rarely offered specific reasons for their objections to the content or pedagogy in reforms, possibly because they had already made the case that the motivation for and goals of reforms were suspect.

\section{$5 \quad$ Implications for Education Leaders}

The three communities of meaning agreed about certain elements of Grades K-12 mathematics and the reforms. In particular, they "spoke each other's language" in terms of their conceptions of mathematics as hierarchical, their belief that basic skills and algorithms are important elements in school mathematics, and their view that students should be taught these skills through the use of direct instruction and student practice. They agreed that some of the characteristics of the reforms were a deemphasis of basic skills, including algorithms, memorization, and practice, and increased emphasis on the use of calculators, group work, manipulatives, and discovery learning through problem solving. Philosophically, all three communities of meaning agreed that human instincts cannot be trusted, a view MTs shared as a part of their secondary traditionalist lens, and I contend that this belief affected all three communities' view of what education can and should look like. These shared common understandings of school mathematics and mathematics education reforms enabled them to see each other as allies in their opposition to reforms. These commonalities have also arguably frustrated mathematics education leaders' attempts to address critics' concerns because despite their similarities, there are fundamental differences between the communities of meaning in the way they perceive school mathematics reforms and their reasons for objecting to them.

The primary lens through which the MTs view school mathematics and the reforms is their conception of mathematics as a domain. The MTs are troubled that reformers are redefining mathematics as a domain and, by extension, mathematics success. They worry that left unchecked school mathematics reforms will fundamentally change the subject with which they strongly identify. The CVs' primary lens is quite different from that of the MTs in that they view school mathematics and the reforms through their conservative worldview. To the CVs, the reforms represent a rejection of their fundamental beliefs and value systems and a subtle, yet perhaps effective, attempt to indoctrinate children into liberal ideology. On the other hand, the ETs simply believe reform pedagogies are ineffective. The ETs' belief is a product of their academic-traditionalist view of education, which is largely shared by the MTs.

By cutting through the noise of specific objections to reforms and concentrating on the primary beliefs that drive each group, leaders may be able to alleviate concerns, or at a minimum, refrain from exacerbating them. Given that all three communities of meaning share a distrust of human instincts, leaders should take care not to base arguments or discussions on assumptions that might not be shared. For example, some parents or other education stakeholders may not share an education leader's assumption that children are naturally curious or have a desire to learn. Being unaware that others might not share this assumption, a leader might provide ineffective arguments for reforms such as arguing that a particular pedagogical practice will capitalize on students' curiosity, or stating that teachers can tap into students' intuitions.

Table 2 summarizes the primary lens and the motivations of each of the communities of meaning. The third column specifies what I call flash points, that is, the terminology or ideas that may appear 
harmless to leaders but are particularly problematic to communities of meaning and could therefore derail a productive discussion.

Table 2. Description of Interpretations of Reforms

\begin{tabular}{|c|c|c|c|}
\hline $\begin{array}{l}\text { Community of } \\
\text { Meaning }\end{array}$ & Primary Lens & $\begin{array}{l}\text { Motivation for } \\
\text { Political Activism }\end{array}$ & Flash Points \\
\hline $\begin{array}{l}{[\mathrm{ET}] \text { Education }} \\
\text { Traditionalists }\end{array}$ & $\begin{array}{l}\text { Traditionalist view of } \\
\text { education }\end{array}$ & Reforms are ineffective & $\begin{array}{lc}-\quad & \text { Algorithms } \\
\text { - } & \text { Conceptual } \\
\text { understanding } \\
\text { - } \quad \text { Drill and kill } \\
\end{array}$ \\
\hline $\begin{array}{l}\text { [MT] Math } \\
\text { Traditionalists }\end{array}$ & View of mathematics & $\begin{array}{l}\text { Reforms redefine } \\
\text { mathematics }\end{array}$ & $\begin{array}{ll}\text { - } & \text { Redefines mathematics } \\
\text { - } & \text { Math is pattern finding }\end{array}$ \\
\hline$[\mathrm{CV}]$ Conservatives & $\begin{array}{l}\text { Conservative } \\
\text { worldview }\end{array}$ & $\begin{array}{l}\text { Reforms are liberal } \\
\text { indoctrination }\end{array}$ & $\begin{array}{l}\text { - } \text { Social justice } \\
\text { - } \text { Multicultural education } \\
\text { - Answer not as } \\
\text { important as process }\end{array}$ \\
\hline
\end{tabular}

The ETs are particularly concerned about a de-emphasis of standard algorithms. It is important to them that these algorithms be mastered to the point of fluency. Leaders should anticipate this concern and predetermine how they will handle this assertion. They may wish to present actual student work that demonstrates the capabilities of students who have generated their own strategies. Additionally, leaders may alleviate the concerns of ETs by arranging an exhibit of local students competently performing mental calculations or solving problems, particularly of the type that have traditionally frustrated adults. Given that the ETs are concerned about the potential costs of reform to traditionally disadvantaged students, leaders should strategically select students whose abilities will be highlighted.

In developing their arguments for the reforms, leaders will be more effective with the ETs if they avoid negative characterizations of traditional approaches. The ETs are sensitive to the contention that traditional mathematics instruction is synonymous to a "drill and kill" approach. They are also frustrated by the implied assumption that traditional mathematics instruction neglects conceptual understanding. The ETs will more likely be placated by evidence of strong student achievement within their local school than by general arguments or citations of current research.

The MTs are threatened if leaders suggest that mathematics education reforms redefine mathematics, a phrase that has sometimes been used to characterize reforms (e.g. Meyer, 2010; Romberg \& Kaput, 1999). Leaders should avoid such characterization and instead focus on how the reforms enable more students to learn real mathematics effectively.

The MTs were also concerned about the use of pattern problems in schools, expressing concern about the inherent ambiguity in such tasks. This concern stems from their view of mathematics as precise and unambiguous. Mathematics education reforms, however, emphasize sense making and reasoning activities that are naturally messy. It is unlikely that an educational leader can convince an MT of the value of student struggle with such tasks, given that MTs suspect the mathematical competence of mathematics educators. Leaders faced with a vocal MT are best advised to seek sympathetic academic mathematicians (of whom there are many) to explicitly lend their support to these activities. While unlikely to satisfy the MT in question, the tactic will likely prevent concern spreading to other groups.

The CVs are sensitive to language and practices that they believe promote liberal ideology. Because the CVs equate the term social justice with liberalism, their conception of what leaders mean when using this term is likely far removed from what is actually intended. Likewise, the CVs generally consider multicultural education to mean practices that they view as unproductive or even harmful. Therefore, leaders might consider avoiding these terms (using descriptive phrases instead) and making clear the reasons that attention is given to such matters in mathematics classrooms. For example, a social justice activity currently in use in some U.S classrooms is Driving While Black or Brown (Gutsein, 2006). This project leverages student interest in the phenomenon of racial profiling to teach topics related to probability and statistics. Education leaders can minimize potential concern of CVs about such a project by first, refraining from characterizing it as a social justice lesson and second, by 
emphasizing the objectivity of statistics and the political neutrality of the teacher with respect to classroom discussions related to the project.

The CVs are particularly troubled by the suggestion that correct answers are unimportant or are less important than mathematical processes, because not only does this appear counterintuitive to them, they associate this belief with relativism, that is, the rejection of absolute truth. Leaders, therefore, should avoid statements that could be interpreted as implying that correct answers are unimportant in mathematics education reforms. Instead, leaders might consider bringing in community business leaders to assure CVs that today's job market requires employees who can communicate their thinking, solve problems, and think critically and flexibly.

All three communities of meaning shared the view that mathematicians are expert in determining the content for school mathematics. For the ETs and the CVs, the arguments of the MTs were compelling, presumably because they were viewed as authorities for the teaching and learning of mathematics. Given that many academic mathematicians at least implicitly support reform mathematics instruction, leaders might minimize the impact of critics' arguments simply by recruiting local mathematicians to publicly support reform instruction and goals. Similar proactive measures might minimize the potential for critics' arguments to permeate the larger community of teachers and parents. For example, leaders can disarm potential critics by pre-emptively voicing critics' concerns as part of their arguments for reform practices. For instance, in addressing the community, a leader may sympathetically acknowledge that parents may find it difficult to help their children with homework but that this means their children are developing understandings and abilities that parents never had the opportunity to achieve. The leader then could reassure parents that teachers and school leaders view parents as the experts in their children's lives. This proactive measure could head off likely concerns from CVs.

\section{Conclusion}

Mathematics education leaders may not have viewed themselves as political operatives, nor wished to be in such a position. In the United States, however, education is inherently political, as recent controversies involving mathematics standards have highlighted. In order to avoid potential political pitfalls associated with school mathematics reforms, and to effectively advance practices that promise higher student achievement, leaders must be politically savvy when working with the community, teachers, and other stakeholders. An awareness of the concerns of potential critics, and the underlying views that drive them, will position leaders to avert or minimize controversies that can undermine their efforts.

\section{References}

1. Adams, M. (2009, May 18). "The nature of conservatism." Available: http://townhall.com/columnists/mikeadams/2009/05/18/the_nature_of_conservatism/page/full

2. Adler, M. J. (1940). "God and the professors: Our education cannot support democracy." Vital speeches of the day, vol 7, no. 4, pp. 98-103.

3. Battista, M. T. (1999). "The mathematical miseducation of America's youth." Phi delta kappan, vol. 80, no. 6, pp. 424-433.

4. Bagley, W. C. (1938). "An essentialist's platform for the advancement of American education." Educational administration and supervision, vol. 24, no. 4, pp. 241-256.

5. Beck, G. (2013, April 8). "What is transformational education?" [Video file]. Available: http://www.glennbeck.com/2013/04/08/watch-what-is-transformational-education/.

6. Becker, J. P. and Jacob, B. (2000). "The politics of California school mathematics: The anti-reform of 1997-99." Phi delta kappan, vol. 81, pp. 529-537.

7. Bubba, P. (2014, March 18). "Common Core math explained by math teacher" [video file]. Available: https://www.youtube.com/watch?v=pYhdh4SmZvI

8. Champion News Online. (2013, July 18). "Common Core: Wrong answers are just fine" [video file]. Available: https://www.youtube.com/watch?v=FCfg1gzQ-UI

9. Chapman, M. J. (2013). "Arbitrary math. Operation Jericho." Available: http://americanheritageresearch.com

10. Conservapedia. (2013). "Conservative values." Available: http://www.conservapedia.com/Conservative_values 
11. Corbin, J. and Strauss, A. (1990). "Grounded theory research: Procedures, canons, and evaluative criteria." Qualitative sociology, vol. 13 no. 1, pp. 3-21.

12. Corbin, J. and Strauss, A. (2008). Basics of qualitative research (3rd ed.). Sage. Dewey, J. (1937a). "President Hutchins' proposals to remake higher education." Social frontier, vol. 3, pp. 103-104.

13. Dewey, J. (1937b). "The higher learning in America." Social frontier, vol. 3, pp. 137-139.

14. Dewey, J. (1941/1988). "Lessons from the war - in philosophy. Address at Cooper Union, New York, December 7, 1941." In J. A. Boydston (Ed.) John Dewey: The Later Works, 1925-1953. Southern Illinois University Press. pp. 313-334.

15. Downing, K. D. (2001). "Conservatism vs. liberalism: Does philosophy really matter?" Available: http://www.conservatismvsliberalism.net/

16.Garelick, B. (2005). "An a-maze-ing approach to math." Education Next, 5(2). Available: http://educationnext.org/anamazeingapproachtomath/.

17. Gutstein, E. (2006). "Driving while black or brown: A math project about racial profiling." In E. Gutstein and B. Peterson (Eds.), Rethinking mathematics: Teaching social justice by the numbers. Rethinking Schools. pp. 16-18.Hirsch, E. D., Jr. (2001). "The roots of the education wars." In T. Loveless (Ed.), The great curriculum debate: How should we teach reading and math? Brookings Institution.

18. Garelick, B. (2013, July 9). Do the 'math wars' really exist? Education News. Retrieved from http://www.educationnews.org/k-12-schools/do-the-math-wars-really-exist/

19.Hirsch, E. D., Jr. (1997). "Why traditional education is progressive." The American Enterprise. 42-45. Retrieved from https://www.heartland.org/publications-resources/publications/why-traditional-education-is-progressive

20. Hutchins, R. M. (1936). "General education." In R. M. Hutchins (Ed.), The higher learning in America. Yale University Press. pp. 59-87

21. Jessica, M. J. (2014, March 26). "Teaching math in bizarro world" [video file]. Available: https://www.youtube.com/watch?v=nHxThdCWWxw

22. Kandel, I. L. (1938). "As essentialists would have it." Parents magazine, vol. 13, no. 6, pp. 66-67.

23.Kohn, A. (1998). "Only for my kid: How privileged parent undermine school reform." Phi delta kappan, vol. 79, pp. $569-577$.

24. Kane, I. M. [imkane2012]. (2014, September 8). "Common Core math makes simple arithmetic as complex as calculus" [video file]. Available: https://www.youtube.com/watch?v=djmtDxTF4ZI

25.Laser, M. (2010, November 29). "Conservatives vs. liberals: Before you indoctrinate your kids, read this." The Christian Science Monitor. Available:

http://www.csmonitor.com/Commentary/Opinion/2010/1129/Conservatives-vs.-liberals-Before-youindoctrinate-your-kids-read-this

26. Lehman College, Multimedia Center. (2011). "Math education reform: Does it add up?" [Video webcast]. Available: http://www.nychold.com

27. Leong, Y. K. (2013). "Mathematics K-12: Crisis in education." Asia Pacific mathematics newsletter, vol. 3, no. 1, pp. 31-40.

28. Limbaugh, R. (2007, April 2). "What the left's anti-bully movement really means." Available: http://www.rushlimbaugh.com/daily/2007/04/02/what_the_left_s_anti_bully_movement_really_means

29. Limbaugh, R. (2012, February 15). "Educator: Parents don’t know best." Available: http://www.rushlimbaugh.com/daily/2012/02/15/educator_parents_don_t_know_best

30. Loveless, T. (Ed). (2001). "Introduction." In The great curriculum debate: How should we teach reading and math? Brookings Institution.

31. Loveless, T. (2004). "Trends in math achievement: The importance of basic skills." Available: http://www2.ed.gov/rschstat/research/progs/mathscience/loveless.html

32. Meyer, D. (2010). "Dan Meyer: Math class needs a makeover." Available: https://www.ted.com/talks/dan_meyer_math_curriculum_makeover?language=en

33. Milgram, J. (n.d.). "Pattern recognition problems in $\mathrm{K}-12 . "$ Available: http://math.stanford.edu/ milgram/education-index.html

34. Morganstern, M. (2013). " $4 \times 3=11$ ? Did school official really say it doesn't matter if students get simple math wrong under Common Core?" Available: http://www.theblaze.com/stories/2013/08/19/rumor-check-4-x-3-11did-school-official-really-say-it-doesnt-matter-if-students-get-simple-math-wrong-under-common-core/

35. National Council of Teachers of Mathematics. (1989). Curriculum and evaluation standards for school mathematics. Author. 
36. National Council of Teachers of Mathematics. (2000). Principles and standards for school mathematics. Author.

37. National Council of Teachers of Mathematics. (2014). Principles to actions. Author.

38. National Governors Association Center for Best Practices, and Council of Chief State School Officers. (2010). Common Core State Standards Mathematics. Available: http://www.corestandards.org/assets/CCSSI_Math\%20Standards.pdf

39. Norton, O. (2011, June 22). "Report suggests improvements to ASD math program" [Web log post]. Available: http://blog.oaknorton.com/report-suggests-improvements-to-asd-math-program-alarming/

40. NVivo qualitative data analysis software; QSR International Pty Ltd. Version 10, 2012.

41. O'Brien, T. C. (1999). "Parrot math." Phi delta kappan, vol. 80, no. 6, pp. 434-438.

42. Pajares, M. F. (1992). "Teachers' beliefs and educational research: Cleaning up a messy construct." Review of educational research, vol. 62, pp. 307-332.

43. Pappas, N. (2003). "Don't just stand there. Do something! (about school mathematics)." Available: http://www.nychold.com/oped-pappas-0309.pdf

44. Philipp, R. A. (2007). "Mathematics teachers' beliefs and affect." In F. K. Lester (Ed.), Second Handbook of Research on Mathematics Teaching and Learning. Information Age. pp. 257-315

45. Pierson, P. (1993). "When effect becomes cause: Policy feedback and political change." World politics, vol. 45, pp. 595-628.

46. Quirk, B. (2002). "A summary view of NCEE math." Available: http://web.archive.org/web/20130430123519/http://wgquirk.com/NCEE.html

47.Raimi, R. A. (2004). "Notes for talk at National Association of Scholars meeting in NYC May 22, 2004: How did it ever come to this?" Available: http://www.math.rochester.edu/people/faculty/rarm/nas_talk.html

48. Reys, R. E. (2001). "Curricular controversy in the math wars: A battle without winners." Phi delta kappan, vol. 83 , no. 3, pp. 255-258.

49. Romberg, T. A. and Kaput, J. J. (1999). "Mathematics worth understanding." In E. Fennema and T. A. Romberg (Eds.), Mathematics classrooms that promote understanding. Lawrence Erlbaum Associates. pp. 3-17.

50. Schoen, H. L., Fey, J. T., Hirsch, C. R., and Coxford, A. (1999). "Issues and options in the math wars." Phi delta kappan, vol. 80, pp. 444-453.

51. Saunders, D. J. (2008). "Return of the math wars." Available: http://www.creators.com/opinion/debrasaunders/return-of-the-math-wars.html

52. Schoenfeld, A. H. (2004). "The math wars." Educational policy, vol. 18, pp. 253-286.

53. Stotsky, S. (2009, November 13). "Who need mathematicians for math, anyway?" Available: http://www.cityjournal.org/2009/eon1113ss.html

54.Talbert, J. E. (2002). "Professionalism and politics in high school teaching reform." Journal of educational change, vol. 3, pp. 339-363.

55. Wagner, P. A. (2014). "The math wars: Communities of meaning within the critics of school mathematics reform" (Doctoral dissertation). Available: UGA electronic theses and dissertations.

56. Weinberger, D. (2011). "Liberals, conservatives, and human nature." Available: http://blog.heritage.org/2011/12/09/liberals-conservatives-and-human-nature/

57. Wu, H. (1999). "The joy of lecturing - with a critique of the romantic tradition of education writing." In S. Krantz (Ed.), How to teach mathematics (pp. 261-271). American Mathematical Society.

58. Wu, H. (2011). "The mis-education of mathematics teachers." Notices of the AMS, vol. 58, no. 3, pp. 372-383.

59.Yannow, D. (2000). Conducting interpretive policy analysis. Sage. 